\title{
Additive and synergistic effects of land cover, land use and climate on insect biodiversity
}

\author{
Ian Oliver $(\mathbb{D} \cdot$ Josh Dorrough • \\ Helen Doherty $\cdot$ Nigel R. Andrew
}

Received: 6 February 2016/ Accepted: 24 June 2016/Published online: 5 July 2016

(C) The Author(s) 2016. This article is published with open access at Springerlink.com

\begin{abstract}
Context We address the issue of adapting landscapes for improved insect biodiversity conservation in a changing climate by assessing the importance of additive (main) and synergistic (interaction) effects of land cover and land use with climate.

Objectives We test the hypotheses that ant richness (species and genus), abundance and diversity would vary according to land cover and land use intensity but that these effects would vary according to climate.

Methods We used a $1000 \mathrm{~m}$ elevation gradient in eastern Australia (as a proxy for a climate gradient)
\end{abstract}

Electronic supplementary material The online version of this article (doi:10.1007/s10980-016-0411-9) contains supplementary material, which is available to authorized users.

I. Oliver (两)

Office of Environment and Heritage,

PO Box U221, Armidale, NSW 2351, Australia

e-mail: ian.oliver2@environment.nsw.gov.au

I. Oliver · J. Dorrough · N. R. Andrew

School of Environmental and Rural Sciences, University

of New England, Armidale, NSW 2351, Australia

H. Doherty

School of Ecosystem and Forest Sciences, University of

Melbourne, Creswick, VIC 3363, Australia

\section{N. R. Andrew}

Insect Ecology Laboratory, Centre for Behavioural and Physiological Ecology, University of New England,

Armidale, NSW 2351, Australia and sampled ant biodiversity along this gradient from sites with variable land cover and land use.

Results Main effects revealed: higher ant richness (species and genus) and diversity with greater native woody plant canopy cover; and lower species richness with higher cultivation and grazing intensity, bare ground and exotic plant groundcover. Interaction effects revealed: both the positive effects of native plant canopy cover on ant species richness and abundance, and the negative effects of exotic plant groundcover on species richness were greatest at sites with warmer and drier climates.

Conclusions Impacts of climate change on insect biodiversity may be mitigated to some degree through landscape adaptation by increasing woody native vegetation cover and by reducing land use intensity, the cover of exotic vegetation and of bare ground. Evidence of synergistic effects suggests that landscape adaptation may be most effective in areas which are currently warmer and drier, or are projected to become so as a result of climate change.

Keywords Climate change - Landscape adaptation . Land cover - Land use - Synergistic effects .

Biodiversity · Insects · Ants - Species richness ·

Species turnover

\section{Introduction}

Within fragmented, human dominated landscapes, native vegetation cover continues to decline and land 
use intensity continues to increase, further threatening terrestrial biodiversity, ecosystems and environmental services (Sala et al. 2000; Oliver and Morecroft 2014). Predicted increases in global mean surface temperatures of $1.4-4.8^{\circ} \mathrm{C}$ by the end of the twenty-first century are likely to exacerbate these threats (IPCC 2014; Williams et al. 2014; CSIRO and Bureau of Meteorology 2015). The importance of these separate threatening processes are well known, but only recently has attention turned to understanding the interactions between them (de Chazal and Rounsevell 2009; Mantyka-Pringle et al. 2012; Staudt et al. 2013; Oliver and Morecroft 2014; Gibb et al. 2015). For example, in 2014, 602 decision makers and scientists were asked to rank priority research questions, that if answered would increase the effectiveness of policies for the management of natural resources in the United States. "How does the configuration of land cover and land use affect the response of ecosystems to climate change?" was ranked 11 th among the top 40 priority questions from a total pool of more than 500 (Fleishman et al. 2011; Rudd and Fleishman 2014).

Despite a dearth of evidence, it is believed that biodiversity in fragmented landscapes is more vulnerable to climate change impacts than those in relatively undisturbed continuous landscapes (Mantyka-Pringle et al. 2012). Therefore, to maintain and restore biodiversity, ecosystems and environmental services into the future, decision makers and scientists must seek to better understand synergistic effects between land cover and land use change and climate change (Mawdsley et al. 2009). Synergistic effects describe the simultaneous actions of separate processes that have a greater total effect than the sum of the individual effects alone (Brook et al. 2008). They are the result of multiplicative interactions between threatening processes such as land use, land cover and climate change in contrast to additive effects.

Observed and predicted effects of climate change on populations, species and ecosystems have been reported in several major reviews (Walther et al. 2002; Root et al. 2003; Bellard et al. 2012; Williams et al. 2014). However, because most research has focused on relatively undisturbed ecosystems, interactions between land cover and land use change and climate change, have largely been ignored. Oliver and Morecroft (2014) found that although some recent studies have investigated the effects of multiple threatening processes on biodiversity (see Eglington and Pearce-Higgins 2012;
Williams et al. 2014), empirical evidence of interactions, or synergies, between threatening processes is rare. Two recent studies have explicitly tested for interactions. Mantyka-Pringle et al. (2012) undertook a meta-analysis of 1319 studies to identify interactions between climate change and habitat loss on biodiversity. They found that, averaged across species and geographic regions, habitat loss and fragmentation effects were greatest in areas with higher mean temperatures and where mean precipitation had decreased over time. Gibb et al. (2015) analysed a global database of 1128 local ant assemblages and similarly found a greater effect of disturbance on ant species richness and evenness in more arid environments.

Risk of species or population extinction may be higher than previously thought where interactions among threatening processes exist (Brook et al. 2008). A failure to account for these interactions could result in the implementation of landscape adaptation strategies that are at best inefficient and at worst detrimental to species persistence (Brook et al. 2008; Staudt et al. 2013). For example, Sala et al. (2000) explored scenarios of global biodiversity change for the year 2100 with and without interactions among the major causes of biodiversity decline. Their analyses highlighted the sensitivity of projected biodiversity change to assumptions about synergies. They concluded that the interactions among stressors represented one of the largest uncertainties in the projection of future global biodiversity change.

Here we address the issue of adapting landscapes for biodiversity conservation in a changing climate by testing the importance of additive (main) and synergistic (interaction) effects of climate, land cover and land use on terrestrial biodiversity. Our study took place in a fragmented landscape, outside of the protected area network, and mostly on private land managed for agricultural production. Within this landscape we expected to observe interactions between land cover and/or land use effects with effects due to climate. We sampled a 1000 m elevation gradient as a proxy for a climate gradient. Contemporary climate gradients (latitude and elevation) are a practical approach for understanding the effects of climate on terrestrial biodiversity and have been used by many authors to predict responses to climate change (see Progar and Schowalter 2002; Andrew et al. 2003; Andrew and Hughes 2004, 2005; Botes et al. 2006; Yates et al. 2011; Frenne et al. 2013). 
We focus on insects, a mega-diverse component of terrestrial biodiversity that performs fundamental ecosystem functions in terrestrial environments. Insects are ectothemic, characterized by small body size and complex life cycles, and so are particularly sensitive to climate (Progar and Schowalter 2002; Andrew 2013). Insect focused climate change research is however scant, especially so in Asia, Africa and Australasia, and in particular where habitats are modified and landscapes are fragmented. Available research has concentrated on changes in abundance and/or distribution shifts of single species due to climate change, most commonly butterflies in Europe (Wilson et al. 2007; Felton et al. 2009), or insects of concern to primary producers (Andrew et al. 2013a).

Within the insects, we target the ants (Family: Formicidae), a ubiquitous and diverse insect group that has received relatively little climate change research (Andrew et al. 2013a; Gibb et al. 2015), and we do so through an investigation of communities rather than single species. Ant communities have a long history of use as indictors of disturbance (Andersen and Majer 2004; Solar et al. 2016) and play crucial roles in ecosystem functioning on all continents except Antarctica; as invertebrate and seed predators, seed dispersers, detritivores, herbivore "farmers", in bioturbation and mutualisms, and as a food source for other invertebrates and vertebrates (Lach et al. 2010). They are fundamental to providing ecosystem services and habitat engineering (Folgarait 1998), and among the insects are diverse and relatively well known. Worldwide, there are more described ant species (at least 15,000, AntWiki 2016), than bird species (at least 9000, http://www.environment. gov.au/node/13867), with many thousands more ant species collected, but awaiting formal description. In Australia, more than 1500 ant species have been described (AntWiki 2016) compared to 828 bird species (http:// www.environment.gov.au/node/13867). Ants are therefore an exemplar taxon for the study of climate and climate change impacts on biodiversity generally, and insects specifically (Andrew 2013).

\section{Methods}

Study area and sites

The study was conducted in northern New South Wales, Australia, and spanned a $270 \mathrm{~km}$ longitudinal, and a $1000 \mathrm{~m}$ elevation gradient (154-1047 m, Fig. 1). Modelled average annual rainfall and maximum temperature at our sites ranged from $530 \mathrm{~mm}$ and $27{ }^{\circ} \mathrm{C}$ in the west to $890 \mathrm{~mm}$ and $20{ }^{\circ} \mathrm{C}$ in the east (Xu and Hutchinson 2011). Rainfall is highest in summer and uniform across other seasons (OEH 2014). Within the study area native vegetation has been extensively cleared with only $31 \%$ of the area described as "intact" (native vegetation in which the structure has not been substantially altered by human activities, or has been altered and has since recovered; OEH 2010; Dillon et al. 2011). The study area contains some of the most fertile soils in Australia and land use is dominated by livestock grazing (of modified pastures $37 \%$, of native vegetation $12 \%$ by area) and cropping (dryland $27 \%$, irrigated $4 \%$ ), with land used minimally for agriculture, or used for conservation, representing $14 \%$ of the region (BRS 2009). Intact native vegetation is dominated by grassy woodlands and dry sclerophyll forests at higher elevations and semi-arid woodlands at low elevations (Keith 2004). Across the study area we established 2-8 sites $(20 \times 50 \mathrm{~m})$ on each of 27 farms to sample the range of land cover and land use states available. Farms were part of an environmental monitoring program and were selected by the local catchment management authority. An additional eight sites located within crown land on travelling stock routes/ reserves (TSRs) were also part of the monitoring program and were included in the study (121 sites in total, see Fig. 1). TSRs varied widely in their land cover and grazing intensity and so tenure was not considered further.

Response variables

Ground-active arthropods were sampled at each site using 10 pitfall traps open for 14 days in summer 2009 (see Supporting Information). More than 210,000 arthropods were collected and sorted into major groups. Ants represented $63 \%$ of all specimens and were further sorted to morphospecies. Morphospecies were identified to genus and where possible species using the keys available at McAreavey (1957), Heterick (2001), McArthur (2010), Heterick and Shattuck (2011) and AntWiki (2016). Mounted specimens were supplied to Dr Steve Shattuck (Australian National Insect Collection, CSIRO, Canberra) for confirmation of identifications and provision of 


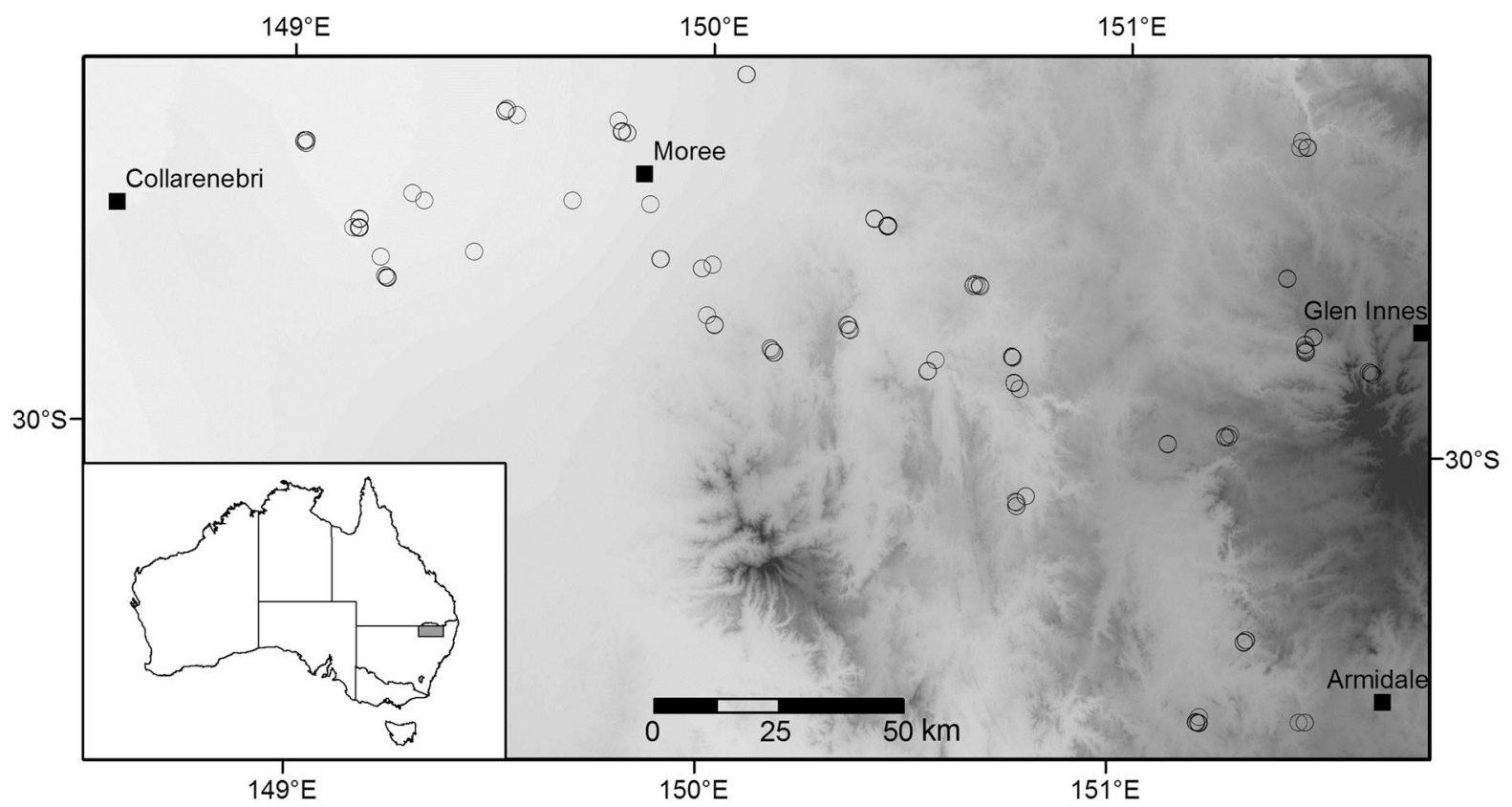

Fig. 1 Study area, site locations and modelled long-term aridity surface (aridity is highest where shading is lightest)

additional species names. Dr Brian Heterick confirmed morphospecies and provided species names for the genus Melophorus. A mounted reference collection was deposited in the Zoology Museum at the University of New England, Armidale.

The (morpho)species dataset (referred to as species from hereon) was used to generate the response variables for ant community structure: species richness (total number of species recorded at each site); genus richness (total number of genera recorded at each site); $\log$ abundance (natural logarithm of the number of ant specimens recorded at each site); and species diversity [Shannon: $\mathrm{H}^{\prime}=-\sum_{\mathrm{i}} \mathrm{p}_{\mathrm{i}} \log _{\mathrm{e}}\left(\mathrm{p}_{\mathrm{i}}\right)$, where $p_{i}$ is the proportion of the total count arising from the ith species (Magurran 1991), calculated using PRIMER V6, Clarke and Gorley (2006)]. The full species by sites matrix (excluding species recorded from only one site) was used to explore responses in ant community composition.

Explanatory variables

Soils

Inherent soil chemistry and texture have a strong association with ant community structure and composition (Boulton et al. 2005). At each site a single soil core was taken at the south-west corner and separated into depths of $0-5$ and $5-10 \mathrm{~cm}$. Field texture was assessed and converted to approximate clay content (range 3.8-65\%) —according to McDonald and Isbell (1998). At each site soil $p H$ was measured for 10 randomly located soil cores bulked at depths $0-5$ and 5-10 cm (range 4.1-7.4). Soils were dried and sieved to $<2 \mathrm{~mm}$ prior to $\mathrm{pH}$ analysis in 1:5 $\mathrm{CaCl}_{2}$ suspension (Rayment and Lyons 2010). Percentage clay content and $p H$ values were averaged across the two depths at each site.

\section{Climate}

For each site's location we generated modelled longterm climate (annual averages/totals for the 30 years, 1976-2005); and recent climate (monthly averages/totals for the 48 months immediately prior to sampling, January 2005-December 2008). We used the 1976-2005 period because it is a standard baseline used for climate change assessments ( $\mathrm{Xu}$ and Hutchinson 2011), and we used the 2005-2008 period to ensure that any effects of more recent climate did not go undetected. We also generated a climate dataset using just the month during which sampling took 
place, and the month prior. We constructed this recent weather dataset because weather conditions varied over the 10 weeks during which all sites were sampled, and this variation may have affected ant activity and, therefore, pitfall trap samples. Site locations were submitted to ANUCLIM V6.1 (Xu and Hutchinson 2011) and modelled climate data extracted at those locations for; average minimum and maximum temperatures $\left({ }^{\circ} \mathrm{C}\right)$, average solar radiation (MJ per $\mathrm{m}^{2}$ ), total rainfall $(\mathrm{mm})$, and total pan evaporation $(\mathrm{mm})$.

Extracted climate data were co-linear $(r> \pm 0.95$, $P<0.001)$ for all pairs of variables within the longterm and the recent climate datasets. For all subsequent statistical modeling we therefore used the single composite climate index-Aridity:

Aridity $=1-\frac{\text { Rain }}{\text { Evap }}$

where Rain and Evap are the total rainfall and pan evaporation in $\mathrm{mm}$ for the period of interest. Our index of aridity ranges from 0 to 1 with more arid environments approaching 1. Aridity integrates rainfall with the effects of temperature, humidity and wind speed so is appropriate for climate change research because: (1) these variables are predicted to change significantly over coming decades (Thuiller 2007; Chown et al. 2010; IPCC 2014), and (2) temperature and water availability are of fundamental importance to insect physiology, behaviour and ecology (Andrew 2013). We did not use potential evapo-transpiration in our aridity index due to its relationship with land cover variables (UNEP 1992). The index of aridity at each temporal scale was significantly correlated $(P<0.001)$ with elevation, longitude and to a lesser extent latitude, (long-term climate (range 0.346-0.742), $r=-0.98,-0.95,0.58$; recent climate (range 0.356-0.788), $r=-0.99,-0.93,0.71$; recent weather (range 0.461-0.821), $r=-0.79,-0.82$, 0.35, respectively, see Figure S1 Supporting Information).

\section{Land cover and land use}

Land cover variables were visually assessed at each site and those submitted to modeling were: canopy cover [sum of percentage crown cover of native overstorey and midstorey woody plants $>1 \mathrm{~m}$ in height (range 0-90\%)]; and bare ground [percentage cover of exposed soil (range 0-97 \%)] (Table 1). Native plant ground cover $(<1 \mathrm{~m}$ in height) and litter cover were significantly correlated with other land cover/use variables so were not submitted to modelling.

Land use variables assessed at each site and submitted to modeling included: a semi-quantitative land use intensity (LUI) index (range 0-0.92), which was based on the sum of scores for cultivation $(C)$ and grazing $(G)$ severity and age:

$L U I=\frac{\left(C_{s}+C_{a}+G_{s}+G_{a}\right)}{12}$

where both severity $(s)$ and age $(a)$ took values between 0 and 3 (Severity: $0=$ no evidence, $1=$ light, $2=$ moderate, $3=$ severe. Age: $0=$ no evidence, old $=1$, not recent $=2$, recent $=3$, see Supporting Information). Scores were allocated based on field assessment and/or landholder interview. A single land use intensity index was preferable to separate grazing and cultivation indices to reduce model complexity, and to provide a greater range of possible scores, with those $>0.5$ revealing both grazing and cultivation histories at sites. The variable exotic groundcover (total projected foliage cover of all non-native vascular plants $<1 \mathrm{~m}$ in height) was also submitted to modeling. High values of exotic groundcover are indicative of a history of heavy grazing and soil disturbance (McIntyre et al. 1995; Dorrough and Scroggie 2008; Lewis et al. 2009) (Table 1). Different land cover and land use states were present across the full environmental gradient (correlation between land cover/use intensity and aridity $r<|0.2|)$.

\section{Statistical modeling}

\section{Ant community structure}

Our modeling approach assessed the importance of additive (main) and synergistic (interaction) effects of climate, land cover and land use on the structure of ant communities. Our a priori hypotheses were that ant richness (species and genus), abundance and diversity would vary according to land cover and land use intensity but that these effects would vary according to climate. We also expected a soil type effect. Prior to model fitting, explanatory variables (Table 1) were converted to z-scores and assessed for evidence of 
Table 1 Climate, land cover and land use intensity variables used in model fitting

\begin{tabular}{|c|c|c|}
\hline Category & Variable (potential range) & Biological justification and other comments \\
\hline \multirow[t]{3}{*}{ Climate } & $\begin{array}{l}\text { Aridity: long-term climate } \\
\quad \text { (continuous variable } 0-1 \text { ) }\end{array}$ & $\begin{array}{l}\text { Combines data on rainfall and evaporation, the latter influenced by temperature, } \\
\text { solar radiation, wind speed and humidity; time-scale biologically meaningful } \\
\text { to meta-population processes. More arid sites have higher values }\end{array}$ \\
\hline & $\begin{array}{l}\text { Aridity: recent climate (continuous } \\
\text { variable } 0-1 \text { ) }\end{array}$ & $\begin{array}{l}\text { As above; time-scale biologically meaningful to demographic processes. Tested } \\
\text { as an alternative to long-term climate in models of total abundance and } \\
\text { species diversity }\end{array}$ \\
\hline & $\begin{array}{l}\text { Aridity: recent weather (continuous } \\
\text { variable } 0-1 \text { ) }\end{array}$ & $\begin{array}{l}\text { As above; time-scale biologically meaningful to feeding and foraging } \\
\text { processes. Tested as an alternative to long-term climate in models of total } \\
\text { abundance and species diversity }\end{array}$ \\
\hline \multirow[t]{2}{*}{ Land cover } & Canopy cover $(0-100 \%)$ & Clearing native trees and shrubs impacts biodiversity (Dorrough et al. 2012) \\
\hline & Bare ground $(0-100 \%)$ & $\begin{array}{l}\text { Increased land use intensity (grazing and farming) reduces native plant } \\
\text { groundcover and litter and increases bare soil cover affecting ground-active } \\
\text { invertebrate biodiversity (Bromham et al. 1999) }\end{array}$ \\
\hline \multirow[t]{2}{*}{ Land use } & $\begin{array}{l}\text { Land use intensity (Integers } 0-12 \\
\text { converted to a proportion) }\end{array}$ & $\begin{array}{l}\text { As above. A semi-quantitative index based on the sum of scores for cultivation } \\
\text { and grazing severity and age (see "Methods" section). More intensively } \\
\text { managed sites have higher values }\end{array}$ \\
\hline & Exotic groundcover $(0-100 \%)$ & $\begin{array}{l}\text { The conversion of ground layer vegetation from native perennial to exotic } \\
\text { dominated is linked with past intensive agricultural land use (Dorrough and } \\
\text { Scroggie 2008) }\end{array}$ \\
\hline \multirow[t]{2}{*}{ Soils } & $\mathrm{pH}(0-14)$ & $\begin{array}{l}\text { Soil chemistry and texture shown to have a more consistent association with ant } \\
\text { community structure and composition than plant richness or biomass (Boulton } \\
\text { et al. 2005) }\end{array}$ \\
\hline & Clay content $(0-100 \%)$ & As above \\
\hline
\end{tabular}

correlation. Models were fitted using mixed effects modeling with the package lme4 (Bates et al. 2014) within the $\mathrm{R}$ statistical environment ( $\mathrm{R}$ Core Team 2014). Mixed models allowed for the specification of a random error term farm to describe the spatial clustering of sites within farms, with each farm given a unique identifier. Semi-variograms of standardized residuals extracted from the full model did not reveal evidence of further spatial auto-correlation for any response variables (see Supporting Information).

All richness response variables were fitted using generalized linear mixed models with a Poisson error distribution and Laplace approximation of the model likelihood. Abundance, although a count, was transformed $\left[\log _{\mathrm{e}}(\mathrm{x}+1)\right]$ and fitted using a linear mixed model (LMM) with a Gaussian distribution. Abundance data were transformed due to strong patterns observed in the residual spread of a Poisson GLMM, which was observed even when a site level random effect was included to account for overdispersion. Species diversity data were also modelled using a LMM with a Gaussian normal distribution. For all
Poisson GLMMs we assessed the degree of overdispersion and apart from the models of the raw abundance counts, none was evident. Exploratory analyses found no support for non-linear relationships (see Supporting Information).

The initial model included the additive effects of all explanatory variables, and the random intercept for Farm ( $(\varepsilon)$ :

$$
\begin{aligned}
\text { Response } \sim & \beta_{1}+\beta_{2} \text { Aridity }+\beta_{3} \text { Canopy } \\
+ & \beta_{4} \text { Bare ground }+\beta_{5} \text { LUI }+\beta_{6} \text { Exotic } \\
& +\beta_{7} p H+\beta_{8} \text { Clay }+ \text { eFarm }
\end{aligned}
$$

where $\beta_{1}$ is the intercept and remaining $\beta_{2}$ through to $\beta_{8}$ are the estimates of the coefficients for each fixed effect.

First we assessed the evidence supporting the hypothesis that the effects of aridity varied according to one or more of the land cover or land use variables. We separately fitted each potential interaction between the climate and land cover or land use fixed effects and estimated the changes in the Akaike 
Information Criterion for a small sample (AICc) (see Burnham and Anderson 2002) compared to the full additive model. The coefficient and profile-likelihood confidence intervals (CIs) were also estimated for each interaction. For models fitted using LMM, we used maximum likelihood (ML) estimation rather than REML to estimate AICc (Zuur et al. 2009), though ML was used to estimate coefficients and associated confidence intervals. Interactions were considered to have some support if they: resulted in a lower AICc than the full additive model; and the estimated effect coefficient for the interaction did not approach 0 ; and the associated profile $95 \%$ CIs did not include 0 . All interactions that met these criteria were retained in the final model fitting. Fixed effect coefficients and associated profile $95 \%$ CIs were estimated from the final model (additive fixed effects plus any supported interactions) using ML estimation. These were used to estimate the direction and strength of the relationship between the response variable and each fixed effect.

Information criteria such as AICc provide estimates of which model within the model set is the most likely given the data, with the aim to identify the most parsimonious model, but provide little indication of the model fit to the data. To provide an indication of the full model goodness-of-fit, we implemented the methods of Nakagawa and Schielzeth (2013) and estimated the variance explained by the fixed effects alone (marginal $R^{2}$ ) and that explained by both the fixed and random effects (conditional $R^{2}$ ). The difference between the marginal and conditional $R^{2}$ indicate the amount of variability explained by the random effects. AICc and model $R^{2}$ were all estimated using the package MuMIn (Barton 2016).

\section{Ant community composition}

Rather than using distance based methods (Warton et al. 2012) or modeling each individual ant species separately, we chose to simultaneously model the entire ant community (with the exception of 64 species only recorded at a single site) using a binomial Generalised Linear Mixed Model (GLMM) with lme4 within the R package. One strength of the GLMM approach to species community composition modeling is the potential for including infrequent species in models. These species can contribute to overall community estimates and their individual species responses can be estimated. This is particularly important in ecological datasets of community composition which often contain few common and many infrequent species.

The presence/absence of ant species was simultaneously modelled across all sites using an approach that has primarily been used for jointly examining species and trait responses (see Gelfand et al. 2003; Dorrough and Scroggie 2008; Pollock et al. 2012). Trait data were unavailable so we modelled the occurrence (presence/absence) of species in response to environmental predictors only. Farm, and Site nested within Farm, were each treated as random intercepts, to account for the correlation among sampling sites. Species was also treated as a random intercept, allowing for differences in species prevalence to be accounted for in the model. In addition, we also specified species random slopes, which allowed each species random effect to vary according to climate, land cover, land use and soil. Hence we simultaneously modelled the overall community level responses, and the individual species deviation from these trends.

Due to model complexity and computational demands our initial full model contained fewer fixed effect explanatory variables than the full models of ant community structure. For each of our climate, land cover, land use and soil categories, we selected the single most important variable based on a Bray Curtis dissimilarity matrix (presence/absence data) submitted to the Bioenv function (Clarke and Ainsworth 1993) in the R package Vegan (Oksanen et al. 2008). Bioenv identified the reduced suite of variables with the greatest rank correlation with the dissimilarity matrix as: aridity (climate), canopy cover (land cover), exotic groundcover (land use) and clay content (soils). Also, to further simplify model complexity we only assessed additive (main) effects of these four variables on ant community composition and did not explore potential interactions among them.

The initial GLMM model consisted of: the additive effects of aridity, canopy cover, exotic groundcover, and clay content as fixed effects; random effect intercepts of site within farm; and random intercept and slope terms for species, with the species random slopes estimated with respect to aridity, canopy cover, exotic groundcover, and clay content. All continuous explanatory variables were converted to z-scores. Ninety-five percent confidence intervals (CIs) around each of the model parameters (fixed and random) were 
estimated using 500 parametric bootstrap simulations. Estimates for the fixed effects were used to infer community level responses to each variable (i.e. the average response across all species), while estimates of the standard deviation for the species random slopes suggested those variables for which among species variation was high. This was visually explored further by plotting individual species conditional modes (also known as the Best Linear Unbiased Predictors, BLUPs) and associated approximate $95 \%$ CIs for each random slope. Variables with relatively large estimates of the standard deviation and substantial among species variation away from a conditional mode of 0 suggested considerable influence on community composition owing to that variable. We also explicitly tested whether the model was improved by incorporating a simple phylogenetic structure within the species random component of the model. This was achieved by nesting species within subfamily and then comparing the model AICc estimates with the initial model.

\section{Results}

More than 132,000 ants were identified to 228 species from 50 genera. An average of 20.8 species (range 6-50), and 11.8 genera (range 5-25) were recorded from sites (see Figure S2 and Figure S3 Supporting Information). More than half of all species belonged to eight genera (Camponotus 29 species, Melophorus 17, Iridomyrmex 16, Pheidole 15, Monomorium 14, Meranoplus 11, Stigmacros 11, and Rhytidoponera 10 ), and more than half of all specimens belonged to two species (Iridomyrmex rufoniger and Rhytidoponera metallica). Eleven species accounted for $85 \%$ of all specimens (I. rufoniger, R. metallica, Pheidole sp.7, Monomorium rothsteini, Iridomyrmex suchieri, Pheidole sp.2, Monomorium sordidum, Nylanderia rosae, Iridomyrmex purpureus, Cardiocondyla nuda and Iridomyrmex mjobergi).

Ant community structure

Synergistic (interaction) effects: do the effects of climate vary depending on land cover and land use?

There was no evidence of varying effects of climate across ranges in indices of land cover or land use for genus richness or species diversity. The AICc for the interactions in these cases were greater than the full additive model and estimates of the response coefficients and associated confidence intervals (CIs) were centered on 0 . The models of species richness and abundance did reveal evidence of a positive interaction between aridity and canopy cover and a negative interaction between aridity and exotic cover for the model of species richness. Model estimates suggested that the positive effects of canopy cover on species richness and abundance were greater in more arid areas, while the negative effects of exotic cover on species richness were greater in more arid areas (Fig. 2). For species richness the model with both interaction terms was well supported compared to the additive model-AICc model weights suggested it was 7 times more likely to be a better model given the data $(\triangle \mathrm{AICc}=3.90)$. In the case of abundance the interaction model had only a marginally lower AICc estimate $(\triangle \mathrm{AICc}=0.87)$ and relative model likelihoods based on AICc model weights suggested it was only 1.5 times more likely than the additive model.

\section{Additive (main) effects}

The model estimates indicated that species richness increased with canopy cover, but decreased with bare ground, land use intensity and exotic groundcover (Fig. 2). Higher clay content and $p H$ were also associated with lower species richness. The fixed effects model for species richness suggested a good fit to the data $\left(R^{2}=0.64\right)$, with additional variation explained by the farm random effect (Table 2).

The model estimates for genus richness were generally consistent with results for species richness (Fig. 2). The model provided a reasonable fit to the data $\left(R^{2}=0.47\right)$ but in this case no additional variation was attributable to the farm random effect (Table 2).

The model estimates indicated that ant abundance increased with aridity (Fig. 2). There were weak trends associated with a negative effect of clay content and $p H$ on abundance. The fixed effects model provided only a poor fit to the data $\left(R^{2}=0.14\right)$, and a large amount of variance was associated with the random farm effect $\left(R^{2}=0.36\right.$, Table 2$)$. We also fitted alternative models of abundance using aridity based on recent climate and recent weather (see "Methods" section). Recent climate resulted in a 
Fig. 2 Fixed effect estimates of model coefficients and $95 \%$ confidence intervals for models of ant richness, diversity and abundance (LUI land use intensity)

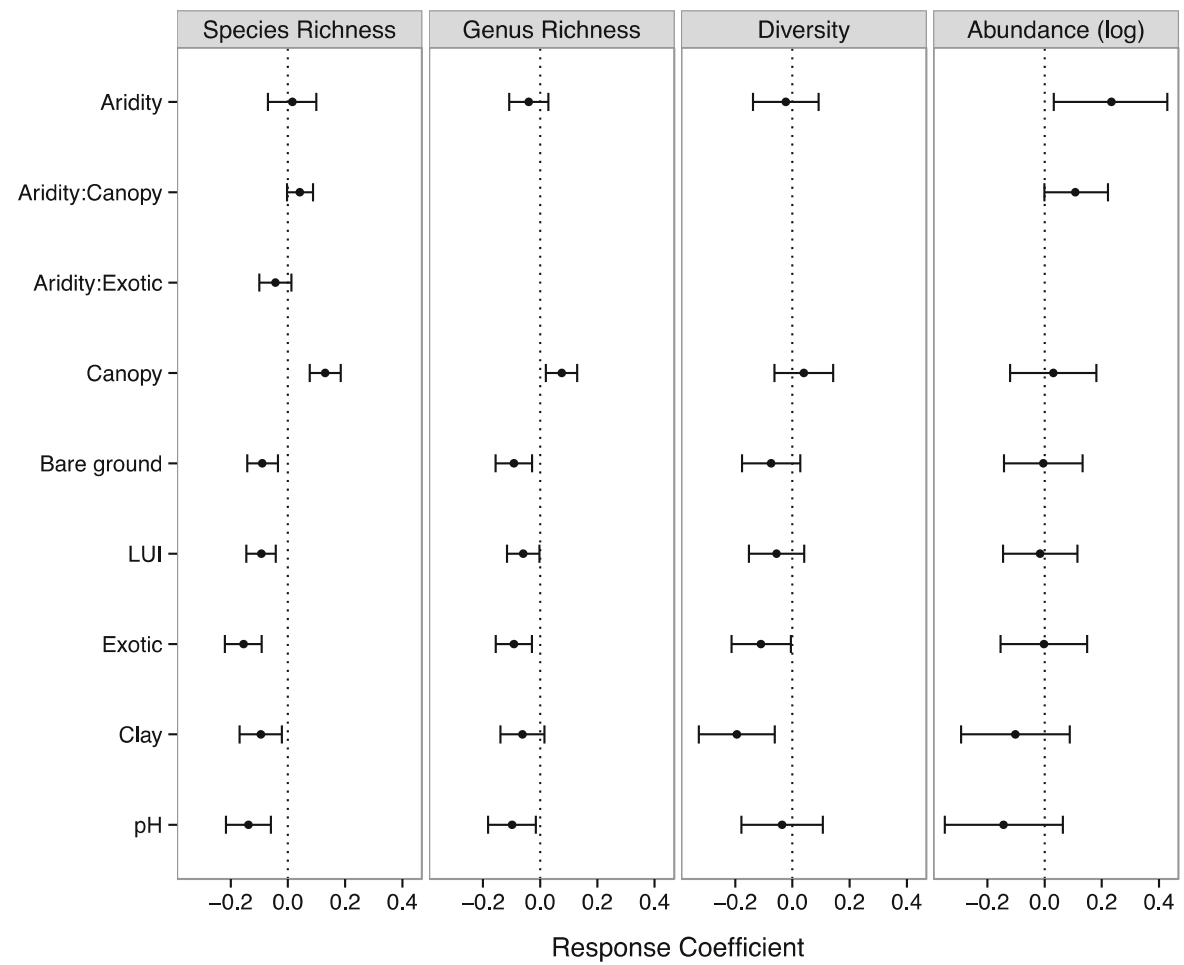

Table 2 Estimates of mixed model fit to the data for models of ant richness, abundance and diversity

\begin{tabular}{lllll}
\hline Response & $R^{2}$ (marginal) & $R^{2}$ (conditional) & Null AICc & Full AICc \\
\hline Species richness & 0.65 & 0.74 & 934.5 & 794.9 \\
Genus richness & 0.47 & 0.47 & 668.2 & 603.7 \\
Abundance $\left(\log _{\mathrm{e}}\right)$ & 0.14 & 0.36 & 262.2 & 264.7 \\
Species diversity & 0.28 & 0.28 & 214.8 & 198.1 \\
\hline
\end{tabular}

Estimates of the variance explained by the fixed effects (marginal $R^{2}$ ) and both the fixed and random effects (conditional $R^{2}$ ) for the full model are shown. The relative fit of the full model (fixed and random effects) compared to the null model (random effects only) is indicated via estimates of the Akaike Information Criterion (AICc). The full model is the additive model and any supported interactions. The full model was not necessarily the "best" model. The null model contains only the farm random effect and no fixed effects. See text for full details

marginally better fit (full model AICc's recent climate $=266.7 \quad c f$ long-term $\quad$ climate $=267.2$ ), though the fixed effect estimate and CI's were almost identical. In contrast, the fit with recent weather was substantially worse (AICc $=274.0$ ).

The model estimates indicated that species diversity declined with increasing exotic groundcover and clay content (Fig. 2). There was little support for remaining variables. The model for species diversity provided a poor fit to the data $\left(R^{2}=0.28\right)$ and no additional variation was attributable to the farm random effect (Table 2). Because abundance affects measures of species diversity, alternative models were also fitted with aridity based on recent climate and recent weather (see "Methods" section), but neither resulted in a lower AICc or improved model fit.

Species richness within genera

Models of species richness within genera were constructed for the eight genera representing more than $50 \%$ of all species (see Figure S4 Supporting Information). Only Camponotus reveled evidence of interactions, and suggested that the already strong 
negative effect of exotic groundcover became increasingly negative in more arid areas (Fig. 3). Model estimates suggested effects of aridity varied among genera, with a positive effect on the richness of Melophorus and Monomorium, and a negative effect on the richness of Pheidole.

There were some consistent trends among genera (Fig. 3). Observed effects of exotic groundcover on species richness were all negative (for Camponotus, Melophorus, Pheidole, Monomorium, Meranoplus, Stigmacros). Observed effects of canopy cover on species richness were all positive (for Camponotus, Stigmacros, Rytidoponera). Observed effects of bare ground were all negative (for Pheidole, Monomorium,
Meranoplus, Stigmacros). The species richness within all genera except Iridomyrmex was therefore affected by land cover and/or land use variables. Soil variables were again important with lower species richness within genera generally associated with increasing clay content (Melophorus, Iridomyrmex, Pheidole), and increasing soil $\mathrm{pH}$ (Melophorus, Monomorium) (Fig. 3). Model fits are provided in Table 3.

Ant community composition

Estimates of AICc suggested that models without subfamily provided a better fit to the data $(\Delta \mathrm{AICc}=18.42)$, so sub-family was not pursued
Fig. 3 Fixed effect estimates of model coefficients and $95 \%$ confidence intervals for models of ant species richness within the most diverse genera ( $L U I$ land use intensity)
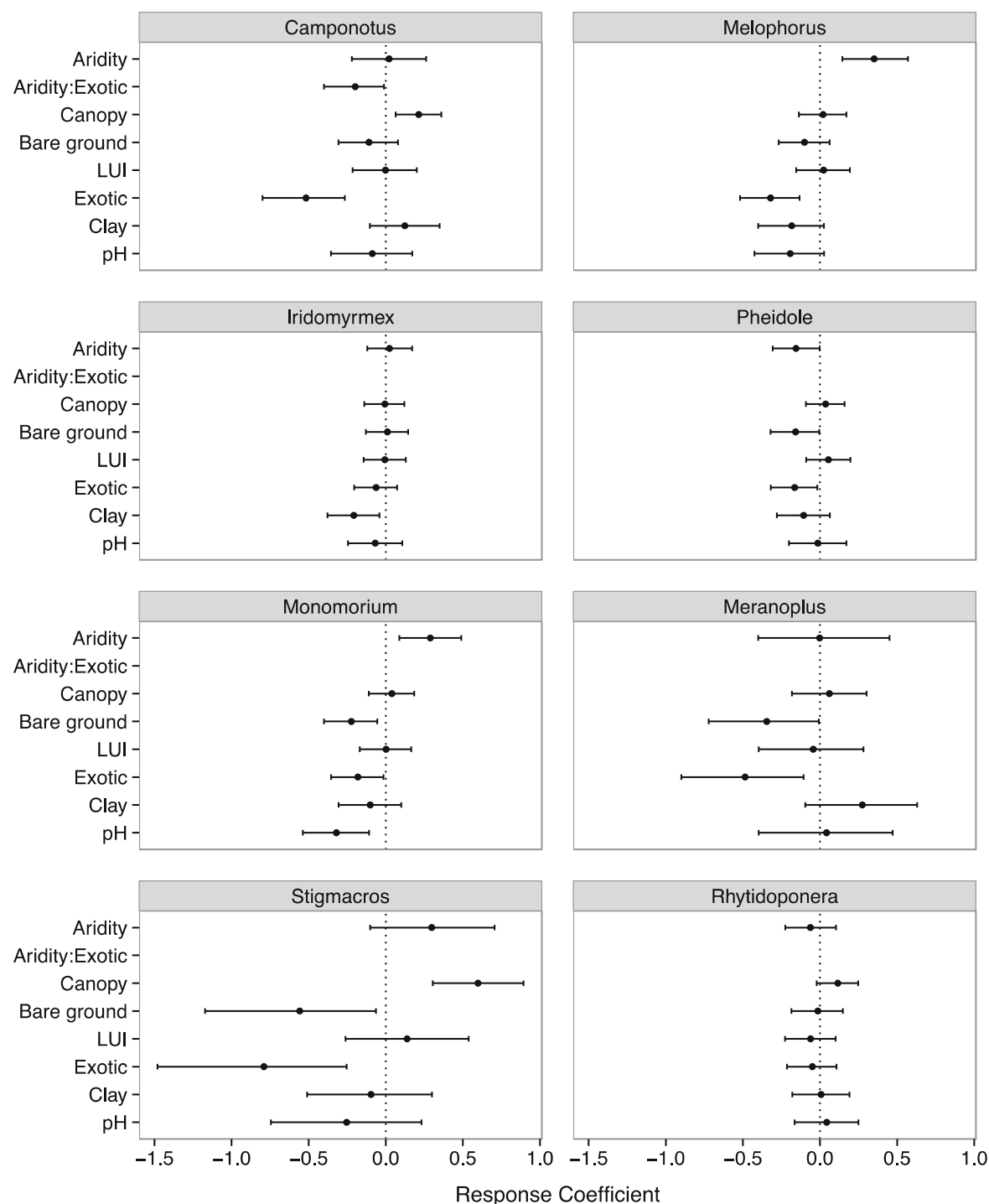
Table 3 Estimates of the goodness-of-fit $\left(R^{2}\right.$, variance explained) for mixed models of species richness within eight ant genera

\begin{tabular}{lll}
\hline Genus & Marginal $R^{2}$ & Conditional $R^{2}$ \\
\hline Camponotus & 0.38 & 0.47 \\
Melophorus & 0.39 & 0.47 \\
Iridomyrmex & 0.18 & 0.18 \\
Pheidole & 0.23 & 0.23 \\
Monomorium & 0.35 & 0.41 \\
Meranoplus & 0.21 & 0.37 \\
Stigmacros & 0.57 & 0.57 \\
Rhytidoponera & 0.08 & 0.08
\end{tabular}

Estimates of $R^{2}$ are shown for the fixed effects (marginal $R^{2}$ ) and fixed and random effects (conditional $R^{2}$ )

further. Estimates of the standard deviation of the random intercept terms (species, farm, and site within farm) revealed that most of the random variation was among species $(\sigma=1.78)$ rather than among sites within farms $(\sigma=0.49)$, or among farms $(\sigma=0.38)$. Most species were infrequent, with low likelihoods of occurrence (reflected in the low fixed effect intercept estimate, Fig. 4a), but some were ubiquitous contributing to the high standard deviation for the species level random intercept (Fig. 4b). Variation in species occurrences was best explained by the random component of the model (marginal $R^{2}=0.07$, conditional $R^{2}=0.66$ ).

The fixed effect estimate for aridity approached zero (Fig. 4a), but the strongly positive standard deviation of the random slope (Fig. 4b) revealed large variation in species response (turnover) along the aridity index gradient. This is further demonstrated in Fig. 5a with species in the upper tail more likely to occur in more arid areas and those in the lower tail more likely to occur in more humid areas.

The fixed effects estimates for both exotic groundcover and clay content were negative, revealing a decline on average in the likelihoods of occurrence of species with increasing exotic groundcover and clay content (Fig. 4a). For canopy cover the effect was positive revealing an increase on average in the likelihoods of occurrence of species with increasing canopy cover (Fig. 4a). The positive random effects for clay content, but to a lesser extent, exotic groundcover and canopy cover, suggested that some species responded differently with respect to these overall predictions (Figs. 4b, 5).

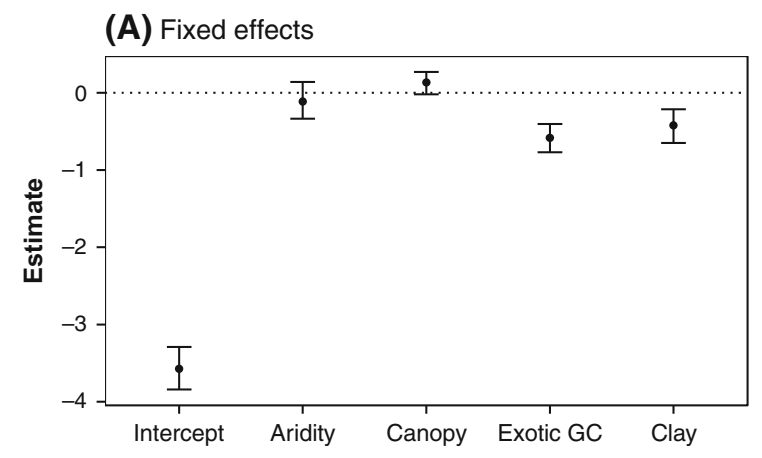

(B) Random effects: Species

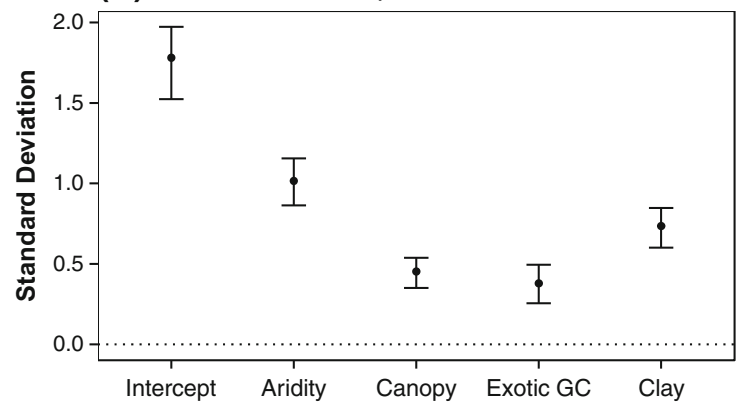

Fig. 4 Fixed effect estimates and $95 \%$ bootstrap confidence intervals (a), and estimates of the standard deviation for species random effects (b) from a binomial GLMM of ant species occurrence. Species random effects include a random intercept and random slopes for aridity, canopy cover, exotic groundcover and clay content (exotic GC exotic groundcover)

Overall our model finds that the turnover in species composition is most strongly associated with climate and soils, evidenced by the large random effect (Figs. 4b, 5). However, main effects showed that decreases in exotic groundcover, and to a lesser extent increases in canopy cover, would increase the probability of occurrence of most species. Decreasing clay content is also expected to increase the probability of occurrence of most species. Yet the high among species variation revealed by the random effects, particularly with respect to clay content, but to some degree canopy cover and exotic groundcover, revealed that some species will respond more strongly, and others less so, than the overall average predictions (Fig. 5).

\section{Discussion}

Within a fragmented human-dominated landscape we explored the notion of adapting landscapes for improved biodiversity conservation, by addressing 


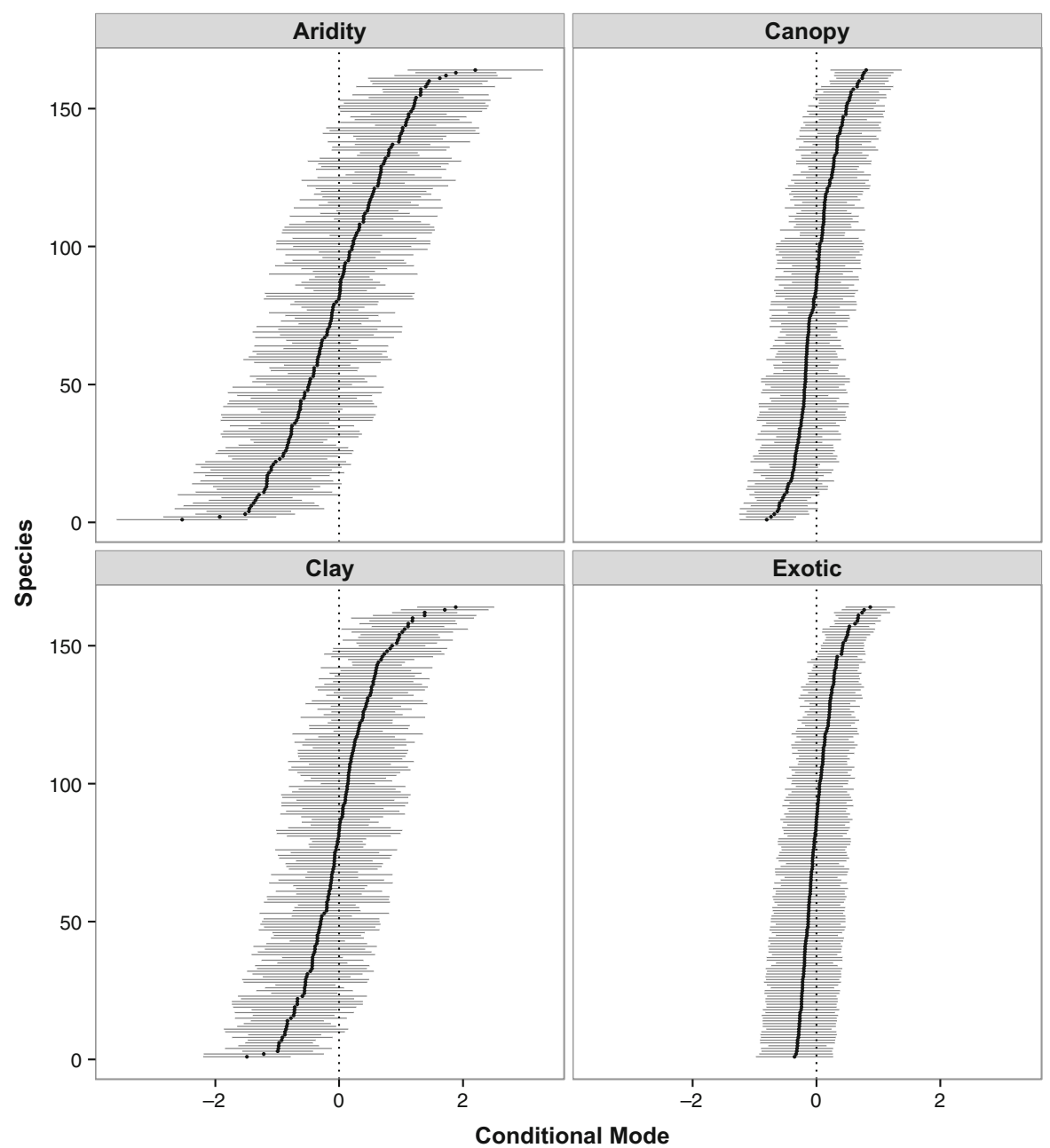

Fig. 5 Estimates of the conditional modes and approximate $95 \%$ confidence intervals for 164 ant species in response to aridity, canopy cover, clay content and exotic groundcover. Estimates are derived from a binomial GLMM random intercept and random slope model of species occurrences. Each bar shows the deviance of each species away from the average response. The further the mode (the dot), is away from 0 then the less like the average response it is. The greater the spread across

the importance of additive (main) and synergistic (interaction) effects of land cover, land use and climate on ant communities. We found strong evidence of main effects due to land cover and land use, but not climate, for the total richness of species and genera recorded from sites. Similar findings have been reported for ant community richness across the Subantarctic-Patagonian transition zone in southern Argentina where vegetation cover and disturbance by cattle were found to be more important than climate (Fergnani et al. 2010). In our study, richness increased all the species the greater the variance among species for that variable. If species cluster near the 0 , then there is little variation among species for that variable and the majority of species are represented by the average response (e.g. exotic ground cover). In contrast for clay content, the fixed effect was negative but there was much variation among species, revealing that most species will still be expected to respond negatively, but some more so and some less so that the average

with canopy cover but decreased with our index of land use intensification, exotic groundcover and bare ground. Local effects of tree and shrub cover loss and habitat disturbance through land use intensification on the structure of ant communities are well documented in Australia (Bromham et al. 1999; Hoffmann and Andersen 2003; Andersen and Majer 2004) and elsewhere (Bestelmeyer and Wiens 1996; Boulton et al. 2005; Solar et al. 2016). We add to this knowledge and provide clear empirical evidence for the potential of landscape adaptation to maintain and 
restore the species richness of ant communities at the site scale.

We hypothesised that our study would reveal that main effects attributable to land cover and land use intensity would vary according to climate, meeting the definition of a synergistic effect. We found that not only did higher native tree and shrub cover, and lower exotic plant groundcover have a general positive effect on ant community species richness, but that these effects interacted with climate to create an even greater effect in hotter and drier areas. Our study is therefore among very few that have demonstrated evidence of interactions or synergistic effects between land cover and/or land use and climate. Importantly, the findings reported by these few studies are consistent and suggest that the effects of land cover and land use intensity change are likely to be greatest in areas which are currently warmer and drier, or are projected to become so (Mantyka-Pringle et al. 2012; Gibb et al. 2015). Implications of these findings for natural resource management in general and landscape adaptation in particular are discussed in the recommendations section below.

Maintaining site-level species richness in a changing climate is an important conservation goal. However, understanding patterns of species turnover along environmental gradients and how these may be affected by climate change is also fundamental to conservation planning and management. As has been found in other studies, our analyses of species composition revealed a large turnover of species along our climate/elevation gradient (Botes et al. 2006; Wilson et al. 2007; Longino and Colwell 2011; Munyai and Foord 2012; Werenkraut and Ruggiero 2012) and our clay content gradient (Boulton et al. 2005; Werenkraut and Ruggiero 2012). So while climate is clearly important, other factors such as soil type also describe important variation in species turnover. However, despite these strong and not unexpected trends, our analyses still revealed additional trends on community composition related to land cover and land use. In agreement with the findings for richness, we found an overall increase in the likelihood of occurrence of individual species associated with increasing canopy cover and decreasing exotic groundcover. We did show that some species will respond more strongly, and others less so, to these overall average predictions. This result demonstrated that considerable variation in species responses was left unexplained by the fixed effects and that other factors need to be explored to further explain among species variation.

Predictions for different species and functional groups

Understanding variability among species and predicting which will respond positively or negatively to climate change, and by how much, is a current challenge for climate change adaptation scientists (Dawson et al. 2011). A new avenue of research is addressing this knowledge gap by focusing on the morphological and functional traits of arthropods and exploring how these traits may predispose different taxa to different responses to climate change and other anthropogenic disturbances (Gibb et al. 2014; Yates et al. 2014). For example, Gibb et al. (2014) found a range of traits of foliage-living spiders were correlated with a $900 \mathrm{~km}$ climate gradient in south-eastern Australian Themeda triandra grasslands. In particular, larger spider species and species that were active hunters (e.g. crab spiders, Thomisidae) were more common in warmer climates. The authors proposed that strong climate-trait correlations may help predict shifts in the functional traits (and therefore species) of assemblages in response to climate change. Future work on the samples collected in this study will similarly address the morphological traits of common ant species to identify how these traits vary along the land-use/cover and climate gradients both within and across species.

Ants have a long-established and stable functional trait typology making them an ideal study group for understanding the extent of general versus idiosyncratic responses to climate and land use change, and land use intensification (Hoffmann and Andersen 2003). They are grouped into seven functional groups at genus and species-group levels based on their responses to environmental stress and disturbance (Andersen 1995). Our results for genera that are characteristic of some of these functional groups suggest a range of potential responses to a warming and drying climate.

The genus Iridomyrmex is ubiquitous and abundant in the Australian environment and is characteristic of the Dominant Dolichoderinae functional group. Iridomyrmex are highly active and aggressive and exert a strong competitive influence on other ants (Andersen 
1995). Species of Iridomyrmex can also have a wide thermal tolerance, for example the widely distributed I. purpureus is surface active at soil surface temperatures ranging from $13{ }^{\circ} \mathrm{C}$ to $63{ }^{\circ} \mathrm{C}$ (Andrew et al. 2013b). Within our study, Iridomyrmex were found at all sites spanning a $1000 \mathrm{~m}$ elevation gradient and represented $40 \%$ of all specimens collected. Their richness was unaffected by climate, land cover or land use intensity (Fig. 3). We would therefore expect climate change to have little impact on species within this dominant functional group.

The genus Camponotus (Subordinate Camponotini functional group) is also ubiquitous in the Australian environment but is behaviorally submissive to the Dominant Dolichoderinae (Andersen 1995). Although its abundance at sites tends to be relatively low, it is a diverse genus (Andersen and Yen 1985), and recorded the most species in our study. Our analyses found strong evidence of declines in the richness of Camponotus as tree and shrub cover decreased and exotic cover increased. We also found that the negative effects of exotic cover on the richness of this genus became more negative in more arid areas (Fig. 3). We therefore suggest that a warming and drying climate may have negative impacts on the Subordinate Camponotini, and that these impacts may be intensified due to the submissive nature of these species when in the presence of the ubiquitous Dominant Dolichoderinae.

Species that may benefit from climate change are those within the Hot-Climate Specialists functional group, dominated by the genera Melophorus, Meranoplus and some Monomorium (Hoffmann and Andersen 2003). Hot-Climate Specialists possess a range of physiological, morphological and behavioural traits which reduce their interaction with other ants, especially the Dominant Dolichoderines (Andersen 1995). In particular, they can be exceptionally thermophilic and forage when few or no other ants are active. For example, the central Australian ant Melophorus bagoti is most active in the field when soil surface temperature is $60{ }^{\circ} \mathrm{C}$, and can tolerate soil surface temperatures up to $70{ }^{\circ} \mathrm{C}$ (Christian and Morton 1992). In contrast, the Dominant Dolichoderinae Iridomyrmex purpueus has been shown to cease foraging when soil surface temperatures exceed $63{ }^{\circ} \mathrm{C}$ (Andrew et al. 2013b).

Within our study, the Hot-Climate Specialists Melophorus and Monomorium increased with our index of aridity, although this was not the case for Meranoplus (Fig. 3). As the climate warms and the surface soil temperatures increase past thermal thresholds earlier in the day, species which are thermophilic but subordinate to Dominant Dolichoderinae will have more opportunities to forage. We might therefore expect that climate change will favour expansions in the distributions of these thermophilic species. This is particularly important for insect biodiversity because recent genetic analyses suggest that Melophorus may actually contain well over 1000 Australian species, and Monomorium may contain 750 Australian species, making them both among the most diverse ant genera worldwide (Andersen 2016).

Recommendations for landscape adaptation within fragmented landscapes

Within our study area, minimum and maximum temperatures are projected to increase by up to $1.0{ }^{\circ} \mathrm{C}$ by 2030 , and by up to $2.7^{\circ} \mathrm{C}$ by 2070 (OEH 2014). A $3.0^{\circ} \mathrm{C}$ change in mean annual temperature corresponds to a shift in isotherms of approximately $300-400 \mathrm{~km}$ in latitude (in the temperate zone) or $500 \mathrm{~m}$ in elevation (Hughes 2000), or half of the elevation gradient explored in this study. Projected changes in climate are therefore expected to result in major changes to the structure, composition and distribution of insect communities in our study area, and indeed globally (see Wilson et al. 2007).

Our study adds to a growing body of evidence suggesting that land managers and policy makers have an opportunity to mitigate against the negative impacts of climate change. Landscape adaptation via management actions directed towards increasing native vegetation cover, and reducing exotic cover and land use intensity have much potential. Oliver and Morecroft (2014) have suggested that landscape adaptation based on these management actions can reduce the annual mean temperature at sites by up to $3.8^{\circ} \mathrm{C}$. Findings by Gibb et al. (2015) suggest that in warmer drier environments reductions in micro-climate that may result from habitat restoration could be equivalent to a change in mean annual temperature of up to $9{ }^{\circ} \mathrm{C}$.

In light of the above we are encouraged by a review of 22 years of recommendations for biodiversity management in a changing climate which found that the most frequent management recommendation for biodiversity conservation in a changing climate was to 
restore habitat (e.g. improve native vegetation condition and increase native vegetation cover) and "soften" management practices within the agricultural matrix (e.g. reducing land use intensity, Heller and Zavaleta 2009; see also Prober et al. 2014). Our study supports these management recommendations, but also suggests that these management actions may be most effective in areas which are currently warmer and drier, or are projected to become so as a result of climate change.

\section{Conclusions}

It has been suggested that within fragmented, human dominated landscapes, science has insufficient knowledge to predict population persistence and species distributions due to climate change, and that practical solutions to biodiversity conservation under a changing climate will be found in adapting the landscape (Opdam and Wascher 2004). Our study does provide new knowledge that may assist with such predictions and demonstrates that landscape adaptation has much potential to mitigate the negative impacts of climate change. In particular, management actions directed towards increasing native vegetation cover, and reducing exotic cover and land use intensity are within our capability. Of particular note, our results support emerging knowledge that due to synergistic effects, landscape adaptation may be most effective in those areas which are currently warmer and drier, or are projected to become so as a result of climate change.

Acknowledgments Fieldwork was undertaken by K. Barham, A. Ede, J. Lemon, W. Martin and L. Mitchell. M. Yates completed the initial sort of all arthropods. M. Hutchinson provided recent climate and recent weather data. M. McNellie provided long-term climate data and Fig. 1. D. Eldridge and S. Travers provided fruitful discussions around analytical approaches and P. Smith supported the original project concept. This manuscript has benefitted from comments provided by T. Auld, S. Croker, M. Dillon, C. McAlpine, P. Smith, G. Summerell, A. York, and two anonymous reviewers. The project received financial support from the Northern Tablelands Local Lands Services, and a NSW Environmental Trust Research Grant to N. R. Andrew and I. Oliver (2010-RD0136).

Open Access This article is distributed under the terms of the Creative Commons Attribution 4.0 International License (http:// creativecommons.org/licenses/by/4.0/), which permits unrestricted use, distribution, and reproduction in any medium, provided you give appropriate credit to the original author(s) and the source, provide a link to the Creative Commons license, and indicate if changes were made.

\section{References}

Andersen AN (1995) A classification of Australian ant communities, based on functional groups which parallel plant life-forms in relation to stress and disturbance. J Biogeogr 22:15-29

Andersen AN (2016) Ant megadiversity and its origins in arid Australia. Aust Ento 55:132-137

Andersen AN, Majer JD (2004) Ants show the way down under: invertebrates as indicators in land management. Front Ecol Environ 2:291-298

Andersen AN, Yen AL (1985) Immediate effects of fire on ants in the semi-arid mallee region of northwestern Victoria. Aust J Ecol 10:25-30

Andrew NR (2013) Population dynamics of insects: impacts of a changing climate. In: Rohde K (ed) The balance of nature and human impact. Cambridge University Press, Cambridge, pp 311-323

Andrew NR, Hughes L (2004) Species diversity and structure of phytophagous beetle assemblages along a latitudinal gradient: predicting the potential impacts of climate change. Ecol Entomol 29:527-542

Andrew NR, Hughes L (2005) Arthropod community structure along a latitudinal gradient: implications for future impacts of climate change. Aust Ecol 30:281-297

Andrew NR, Hill SJ, Binns M, Bahar MH, Ridley EV, Jung MP, Fyfe C, Yates M, Khusro M (2013a) Assessing insect responses to climate change: what are we testing for? where should we be heading? PeerJ 1:e11. doi:10.7717/ peerj.11

Andrew NR, Hart RA, Jung MP, Hemmings Z, Terblanche JS (2013b) Can temperate insects take the heat? A case study of the physiological and behavioural responses in a common ant, Iridomyrmex purpureus (Formicidae), with potential climate change. J Insect Phys 59:870-880

Andrew NR, Rodgerson L, Dunlop M (2003) Variation in invertebrate-bryophyte community structure at different spatial scales along altitudinal gradients. J Biogeogr 30:731-746

AntWiki (2016) http://www.antwiki.org/wiki. Accessed Jan 2016

Barton K (2016) MuMIn: multi-model inference. R package version 1.15.6. http://CRAN.R-project.org/package= MuMIn

Bates D, Maechler M, Bolker B, Walker S (2014) lme4: linear mixed-effects models using Eigen and S4. R package version 1.1-7. http://CRAN.R-project.org/package=lme4

Bellard C, Bertelsmeier C, Leadley P, Thuiller W, Courchamp F (2012) Impacts of climate change on the future of biodiversity. Ecol Lett 15:365-377

Bestelmeyer BT, Wiens JA (1996) The effects of land use on the structure of ground-foraging ant communities in the Argentine Chaco. Ecol Appl 6:1225-1240

Botes A, McGeoch MA, Robertson HG, Niekerk AV, Davids HP, Chown SL (2006) Ants, altitude and change in the northern Cape Floristic Region. J Biogeogr 33:71-90 
Boulton AM, Davies KF, Ward PS (2005) Species richness, abundance, and composition of ground-dwelling ants in northern California grasslands: role of plants, soil, and grazing. Env Entomol 34:96-104

Bromham L, Cardillo M, Bennett AF, Elgar MA (1999) Effects of stock grazing on the ground invertebrate fauna of woodland remnants. Aust J Ecol 24:199-207

Brook BW, Sodhi NS, Bradshaw CJA (2008) Synergies among extinction drivers under global change. Trends Ecol Evol 23:453-460

BRS (2009) Land use summary border rivers/Gwydir NRM Region-NSW. Catchment scale land use mapping for Australia. Update May 2009 dataset. Bureau of Rural Sciences. http://www.daff.gov.au/abares/aclump/pages/ land-use/catchment-scale-land-use-reports.aspx. Accessed July 2015

Burnham KP, Anderson DR (2002) Model selection and multimodel inference: a practical information-theoretic approach, 2nd edn. Springer, New York

Chown SL, Gaston KJ, van Kleunen M, Clusella-Trullas S (2010) Population responses within a landscape matrix: a macrophysiological approach to understanding climate change impacts. Evol Ecol 24:601-616

Christian KA, Morton SR (1992) Extreme thermophilia in a central Australian ant, Melophorus bagoti. Physiol Zool 65:885-905

Clarke KR, Ainsworth M (1993) A method of linking multivariate community structure to environmental variables. Mar Ecol Prog Ser 92:205-219

Clarke KR, Gorley RN (2006) PRIMER. PRIMER-E Ltd, Plymouth, England

CSIRO and Bureau of Meteorology (2015) Climate change in Australia. http://www.climatechangeinAustralia.gov.au/. Accessed Apr 2016

Dawson TP, Jackson ST, House JI, Prentice IC, Mace GM (2011) Beyond predictions: biodiversity conservation in a changing climate. Science 332:53-58

de Chazal J, Rounsevell MDA (2009) Land-use and climate change within assessments of biodiversity change: a review. Glob Environ Change 19:306-315

Dillon M, McNellie M, Oliver I (2011) Assessing the extent and condition of native vegetation in NSW, Monitoring, evaluation and reporting program, Technical report series, Office of Environment and Heritage, Sydney. http://www. environment.nsw.gov.au/resources/soc/20110713NativeVeg TRS.pdf. Accessed Nov 2014

Dorrough J, Scroggie MP (2008) Plant responses to agricultural intensification. J Appl Ecol 45:1274-1283

Dorrough J, McIntyre S, Brown G, Stol J, Barrett G, Brown A (2012) Differential responses of plants, reptiles and birds to grazing management, fertilizer and tree clearing. Aust Ecol 37:569-582

Eglington SM, Pearce-Higgins JW (2012) Disentangling the relative importance of changes in climate and land-use intensity in driving recent bird population trends. PLoS ONE 7:e30407

Felton A, Fischer J, Lindenmayer DB, Montague-Drake R, Lowe AR, Saunders D, Felton AM, Steffen W, Munro NT, Youngentob K, Gillen J (2009) Climate change, conservation and management: an assessment of the peer- reviewed scientific journal literature. Biodivers Conserv 18:2243-2253

Fergnani PN, Sackmann P, Ruggiero A (2010) Richness-environment relationships in epigaeic ants across the Subantarctic-Patagonian transition zone. Insect Conserv Divers 3:278-290

Fleishman E, Blockstein DE, Hall JA, Mascia MB, Rudd MA, Scott JM, Sutherland WJ, Bartuska AM, Brown AG, Christen CA, Clement JP (2011) Top 40 priorities for science to inform US conservation and management policy. Bioscience 61:290-300

Folgarait PJ (1998) Ant biodiversity and its relationship to ecosystem functioning: a review. Biodivers Conserv $7: 1221-1244$

Frenne P, Graae BJ, Rodríguez-Sánchez F, Kolb A, Chabrerie O, Decocq G, Kort H, Schrijver A, Diekmann M, Eriksson O, Gruwez R (2013) Latitudinal gradients as natural laboratories to infer species' responses to temperature. J Ecol 101:784-795

Gelfand AE, Silander JA Jr, Wu S, Latimer A, Lewis PO, Rebelo AG, Holder M (2003) Explaining species distribution patterns through hierarchical modeling. Bayesian Anal $1: 1-35$

Gibb H, Muscat D, Binns MR, Silvey CJ, Peters RA, Warton DI, Andrew NR (2014) Responses of foliage-living spider assemblage composition and traits to a climatic gradient in Themeda grasslands. Aust Ecol. doi:10.1111/aec.12195

Gibb H, Sanders NJ, Dunn RR, Watson S, Photakis M, Abril S, Andersen AN, Angulo E, Armbrecht I, Arnan X, Baccaro FB (2015) Climate mediates the effects of disturbance on ant assemblage structure. Proc R Soc B 282:20150418

Heller NE, Zavaleta ES (2009) Biodiversity management in the face of climate change: a review of 22 years of recommendations. Biol Conserv 142:14-32

Heterick BE (2001) Revision of the Australian ants of the genus Monomorium (Hymenoptera: Formicidae). Inv Taxon 15:353-459

Heterick BE, Shattuck S (2011) Revision of the ant genus Iridomyrmex (Hymenoptera: Formicidae). Zootaxa 2845:1-174

Hoffmann BD, Andersen AN (2003) Responses of ants to disturbances in Australia, with particular reference to functional groups. Aust Ecol 28:444-464

Hughes L (2000) Biological consequences of global warming: is the signal already apparent? Trends Ecol Evol 15:56-61

IPCC (2014) Climate change 2014 synthesis report. Summary for policy makers. Intergovernmental Panel on Climate Change. http://www.ipcc.ch/. Accessed Dec 2014

Keith DA (2004) Ocean shores to desert dunes: the native vegetation of New South Wales and the ACT. Department of Environment and Conservation, Sydney

Lach L, Parr CL, Abbott KL (2010) Ant ecology. Oxford University Press, New York

Lewis T, Clarke PJ, Whalley RD, Reid N (2009) What drives plant biodiversity in the clay floodplain grasslands of NSW? Range J 31:329-351

Longino JT, Colwell RK (2011) Density compensation, species composition, and richness of ants on a neotropical elevational gradient. Ecosphere 2:Article 29

Magurran AE (1991) Ecological diversity and its measurement. Chapman and Hall, London 
Mantyka-Pringle CS, Martin TG, Rhodes JR (2012) Interactions between climate and habitat loss effects on biodiversity: a systematic review and meta-analysis. Glob Change Biol 18:1239-1252

Mawdsley JR, O'Malley R, Ojima DS (2009) A review of climate-change adaptation strategies for wildlife management and biodiversity conservation. Conserv Biol 23:1080-1089

McAreavey JJ (1957) Revision of the genus Stigmacros Forel. Mem Natl Mus Vict 21:7-64

McArthur A (2010) A guide to Camponotus ants of South Australia. South Australian Museum, Adelaide

McDonald RC, Isbell RF (1998) Soil profile. In: McDonald RC, Isbell FF, Speight JG, Walker J, Hopkins MS (eds) Australian soil and land survey field handbook, 2nd edn. CSIRO Publishing, Canberra, pp 103-152

McIntyre S, Lavorel S, Tremont RM (1995) Plant life-history attributes: their relationship to disturbance response in herbaceous vegetation. J Ecol 83:31-44

Munyai TC, Foord SH (2012) Ants on a mountain: spatial, environmental and habitat associations along an altitudinal transect in a centre of endemism. J Insect Conserv 16:677-695

Nakagawa S, Schielzeth H (2013) A general and simple method for obtaining R2 from generalized linear mixed-effects models. Methods Ecol Evol 4:133-142

OEH (2010) State of the catchments 2010, Border RiversGwydir Region, Native Vegetation. Office of Environment and Heritage, Sydney. http://www.environment.nsw.gov. au/resources/soc/borderrivers/10359BRGnativeveg.pdf. Accessed Nov 2014

OEH (2014) New England North West climate change snapshot. Office of Environment and Heritage, Sydney. http:// climatechange.environment.nsw.gov.au/Climate-projectionsfor-NSW/Climate-projections-for-your-region/New-EnglandNorth-West-Climate-Change-Downloads. Accessed Dec 2014

Oksanen J, Kindt R, Legendre P, O’Hara B, Stevens MH (2008) The vegan package. Community ecology package. http:// ocw.um.es/ciencias/geobotanica/otros-recursos-1/documentos/ vegan.pdf. Accessed June 2016

Oliver TH, Morecroft MD (2014) Interactions between climate change and land use change on biodiversity: attribution problems, risks, and opportunities. WIREs Clim Change $5: 317-335$

Opdam P, Wascher D (2004) Climate change meets habitat fragmentation: linking landscape and biogeographical scale levels in research and conservation. Biol Conserv 117:285-297

Pollock LJ, Morris WK, Vesk PA (2012) The role of functional traits in species distributions revealed through a hierarchical model. Ecography 35:716-725

Prober SM, Williams KJ, Harwood TD, Doerr VAJ, Jeanneret T, Manion G, Ferrier S (2014) Helping biodiversity adapt: supporting climate adaptation planning using a community-level modeling approach. CSIRO Land and Water Flagship, Canberra. www.AdaptNRM.org. Accessed Jan 2016

Progar RA, Schowalter TD (2002) Canopy arthropod assemblages along a precipitation and latitudinal gradient among Douglas-fir Pseudotsuga menziesii forests in the Pacific Northwest of the United States. Ecography 25:129-138
R Core Team (2014) R: a language and environment for statistical computing. R Foundation for Statistical Computing, Vienna, Austria. http://www.R-project.org/

Rayment GE, Lyons DJ (2010) Soil chemical methods-Australasia. CSIRO Publishing, Melbourne

Root TL, Price JT, Hall KR, Schneider SH, Rosenzweig C, Pounds JA (2003) Fingerprints of global warming on wild animals and plants. Nature 421:57-60

Rudd MA, Fleishman E (2014) Policymakers' and scientists' ranks of research priorities for resource-management policy. Bioscience 64:219-228

Sala OE, Chapin FS, Armesto JJ, Berlow E, Bloomfield J, Dirzo R, Huber-Sanwald E, Huenneke LF, Jackson RB, Kinzig A, Leemans R (2000) Global biodiversity scenarios for the year 2100. Science 287:1770-1774

Solar R, Barlow J, Andersen AN, Schoereder JH, Berenguer E, Ferreira JN, Gardner TA (2016) Biodiversity consequences of land-use change in the Amazon: a multi-scale assessment using ant communities. Biol Conserv 197:98-107

Staudt A, Leidner AK, Howard J, Brauman KA, Dukes JS, Hansen LJ, Paukert C, Sabo J, Solórzano LA (2013) The added complications of climate change: understanding and managing biodiversity and ecosystems. Front Ecol Environ 11:494-501

Thuiller W (2007) Climate change and the ecologist. Nature 448:550-552

UNEP (1992) World atlas of desertification. Edward Arnold, London

Walther GR, Post E, Convey P, Menzel A, Parmesan C, Beebee TJ, Fromentin JM, Hoegh-Guldberg O, Bairlein F (2002) Ecological responses to recent climate change. Nature 416:389-395

Warton DI, Wright ST, Wang Y (2012) Distance-based multivariate analyses confound location and dispersion effects. Methods Ecol Evol 3:89-101

Werenkraut V, Ruggiero A (2012) Altitudinal variation in the taxonomic composition of ground-dwelling beetle assemblages in NW Patagonia, Argentina: environmental correlates at regional and local scales. Insect Conserv Divers. doi:10.1111/j.1752-4598.2012.00190.x

Williams KJ, Prober SM, Harwood TD, Doerr VAJ, Jeanneret T, Manion G, Ferrier S (2014) Implications of climate change for biodiversity: a community-level modeling approach. CSIRO Land and Water Flagship, Canberra. www. AdaptNRM.org. Accessed Jan 2016

Wilson RJ, Gutierrez D, Gutierrez J, Monserrat VJ (2007) An elevational shift in butterfly species richness and composition accompanying recent climate change. Glob Change Biol 13:1873-1887

Xu T, Hutchinson M (2011) ANUCLIM version 6, users guide. Australian National University, Canberra

Yates ML, Gibb H, Andrew NR (2011) Habitat characteristics may override climatic influences on ant assemblage composition: a study using a $300-\mathrm{km}$ climate gradient. Aust $\mathrm{J}$ Zool 59:332-338

Yates ML, Andrew NR, Binns M, Gibb H (2014) Morphological traits: predictable responses to macrohabitats across a $300 \mathrm{~km}$ scale. PeerJ 2:e271

Zuur A, Ieno EN, Walker N, Saveliev AA, Smith GM (2009) Mixed effects models and extensions in ecology with R. Springer, New York 